\title{
Retrospective study to identify trigeminal-cervical ocular referred pain as a new causative entity of ocular pain
}

\author{
Scheffer CG Tseng' \\ Anny MS Cheng ${ }^{1,2}$ \\ Yao $\mathrm{Fu}^{3}$
}

'Ocular Surface Center, ${ }^{2}$ Florida International University, Herbert Wertheim College of Medicine, Miami, FL, USA; ${ }^{3}$ Department of Ophthalmology, Ninth People's Hospital, Medical School of Shanghai Jiaotong University, Shanghai, People's Republic of China
Correspondence: Scheffer CG Tseng Ocular Surface Center, 7000 SW 97th Avenue, Suite 213, Miami, FL 33173, USA Tel +l $305274 \mid 299$

Fax +I 3052741297

Email stseng@ocularsurface.com
This article was published in the following Dove Press journal: Journal of Pain Research

25 July 2017

Number of times this article has been viewed

Purpose: To determine the prevalence and clinical characteristics of trigeminal-cervical (TC) ocular referred pain.

Methods: A retrospective study of 1,680 patients seen during 2002-2010 was performed in an ocular surface specialty center to identify patients with or without TC pain defined as ocular pain with ipsilateral trigger points located at the occipital region. Patients with refractory TC pain despite topical anesthetics and conventional treatments received interventional injection to each trigger point. Results: A total of 81 (4.8\%) patients (study group) with TC pain and 241 patients (control group) without TC pain were identified out of the 1,680 patients over an 8 year period. There was no difference in age, gender, prior surgeries, medications, non-pain symptoms, pain laterality, and concomitant ocular diseases between the 2 groups. Multivariate regression analysis showed that patients with TC pain had a significant correlation with persistent deep ocular pain, ipsilateral trigger points $\left(f^{2}=99, p<0.001\right)$ but not headaches $\left(f^{2}=0.09, p=0.5\right)$. Injection at the trigger points achieved complete or partial pain resolution with a low recurrence rate in 43 of $45(96 \%)$ patients with TC pain.

Conclusion: TC pain defined herein may be a different entity of ocular pain and can indeed be differentiated from other ocular pain by the referral character so that one may avoid mislabeling it as undetermined or as a reason to unnecessarily overtreat concomitant ocular diseases.

Keywords: headache, new ocular pain, referred pain, trigeminal-cervical, trigger point, occipital neuralgia

\section{Introduction}

Ocular pain located in the eye, periorbital, or retro-orbital areas with or without headaches is a common complaint from patients prompting an ophthalmic clinic visit. ${ }^{1}$ In patients complaining predominantly about ocular pain, nociceptive pain ${ }^{2,3}$ and neuropathic pain ${ }^{4}$ of the eye origin have been recognized. However, one less recognized cause of ocular pain is the ocular referred pain, i.e., the pain is felt at eye but the pain source is originated distantly. Referred pain is caused by highly complex nerve transmission between the peripheral and central nervous systems. ${ }^{5}$ Anatomically, the nociceptive fibers from the ocular region transmit a pain sensation via the ophthalmic branch (V1) of the trigeminal nerve to the trigeminal subnucleus caudalis $\left(\mathrm{V}_{\mathrm{C}}\right)$ and ipsilateral upper cervical spinal cord $\left(\mathrm{C}_{1-2}\right)$. The convergence of any pain mediated by nociceptive fibers from afferent occipital/cervical $\left(\mathrm{C}_{1-2}\right)$ to the same region (hereafter defined as trigeminal-cervical [TC]) may constitute the anatomical basis to elicit ipsilateral ocular referred pain. ${ }^{6-9}$ 
Trigger points are defined as hyperirritable spots that elicit local tenderness or referred pain that cannot be explained by findings on neurological examination. In the eye, several studies have reported that referred pain elicited by trigger points contributes to pain perception in the head, ${ }^{10,11}$ while an example of referred pain as the cause of unexplained ocular pain was first reported in $1954^{12}$ and subsequently described in a large series of 30 cases by Knox and Mustonen ${ }^{13}$ in 1975. In the latter study, the authors noted that such pain had been overlooked by prior patients' visits to several physicians, including ophthalmologists. Such pain is believed to be "referred" in nature because of the presence of trigger points in the occipital scalp area and the permanent pain relief encountered after a single injection of anesthetic into the trigger point. Bode ${ }^{14}$ in 1979 further reported 16 cases with the main complaint of orbital or periorbital pain secondary to "neuritis" in the skull base (region between the occipital protuberance and the mastoid process) and the subsequent relief by regional nerve block. Since then, similar findings have been reported in few isolated case reports. ${ }^{15,16}$ It remains unclear whether the aforementioned ocular referred pain might be a unique TC ocular referred pain (hereafter TC pain for short). To address these questions, a retrospective review of patients who were referred to an ocular surface specialty clinic with a variety of ocular surface diseases since its inception in 2002 was carried out. This was done to determine whether TC pain can be an overlooked cause of ocular referred pain.

\section{Methods}

\section{Study design and subjects}

This study was approved by the ethics committee of the Ocular Surface Research and Education Foundation (Miami,
FL, USA) to retrospectively review 1,680 patients who were consecutively seen from the inception of the Ocular Surface Center (Miami, FL, USA), a center that is specialized in the diagnosis and treatment of difficult and complex ocular diseases, from 2002 to 2010. Following the Tenets of the Declaration of Helsinki, written informed consent was obtained from all patients as a routine. For those complaining of ocular pain, their pain characteristics and associated symptoms were routinely and uniformly assessed according to a questionnaire. From the medical records of these eligible patients, we also retrieved data regarding demographics, past history, previous surgeries, medications, concomitant ocular and systemic diseases, and present illness.

\section{Diagnostic criterion for TC pain}

Diagnosis of TC pain was based on the criterion of presence of trigger points located over external occipital bony protuberance points ipsilateral to the ocular pain. Finger pressing trigger points elicited local tenderness and radiating pain to the eye, resulting in "the patient to jump or hyperextend the back and neck" as described by Knox and Mustonen ${ }^{13}$ (Figure 1A). Different locations of trigger points were systemically surveyed in occipital, neck, shoulder, and elbow in both sides of the body (Figure 1).

\section{Intervention}

Patients with refractory ocular pain, despite topical anesthetics and conventional treatments, might have received an injection to each trigger point. After the trigger points were identified, e.g., over external occipital bony protuberance, they were cleaned with alcohol pad and injected by inserting the needle all the way to the bony protrusion, away from

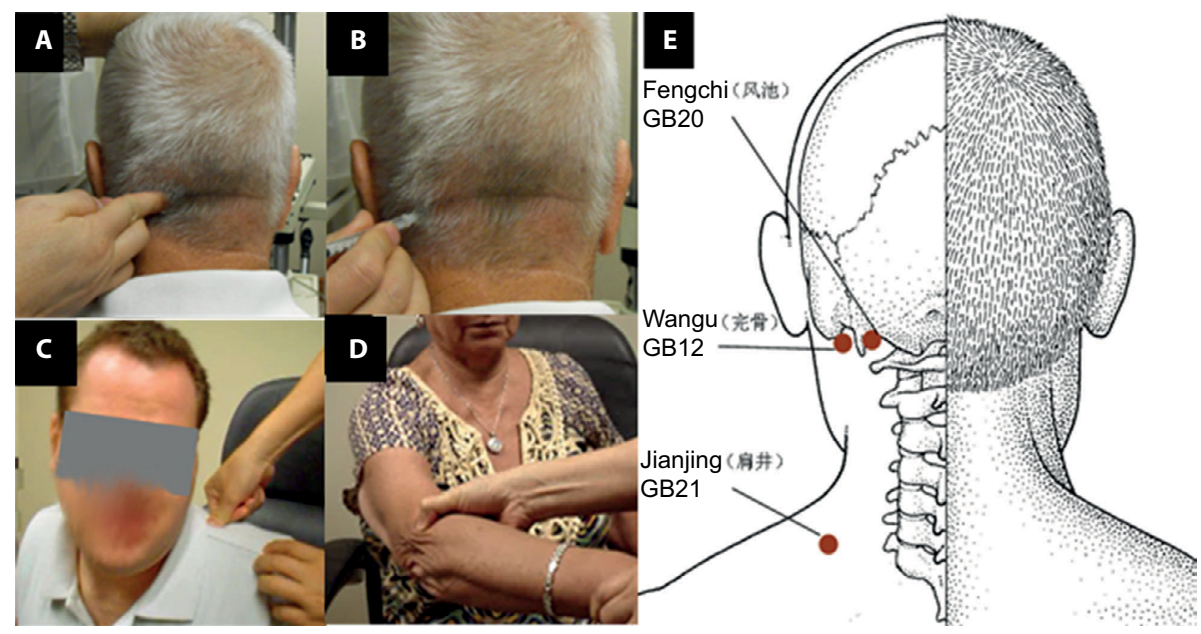

Figure I Trigger points and trigger points injection.

Notes: (A) Trigger point at the occipital area over the external occipital protuberance; (B) injection to occipital trigger point; (C) trigger point at the shoulder area where the trapezus muscle is attached; (D) trigger point at the elbow area over the lateral epicondyle of the humerus bone; and (E) acupuncture points of GB20, GBI2, and GB2I. 
which the needle was withdrawn to the tendon/muscle complex. After the plunger was pulled back to ensure no blood return, $0.5 \mathrm{~mL}$ of an equal mixture $(\mathrm{V} / \mathrm{V})$ of triamcinolone acetonide $(40 \mathrm{mg} / \mathrm{mL}$; Bristol-Myers Squibb, New York, NY, USA) and 2\% lidocaine (Hospira, Inc., Lake Forest, IL, USA) (Figure 1B) was injected to each trigger point.

\section{Outcome measures}

Clinical characteristics including age, gender, prior surgeries, medications, non-pain symptoms, concomitant ocular diseases, headache, pain characteristics, and laterality were compared between the patients with and without TC pain. The locations of trigger points that elicited local tenderness and radiating pain to the eye were compared. The pain response for patients with refractory TC pain who received trigger point injection was assessed as completely resolved, partially resolved, unchanged or worse in the follow-up visits. Pain recurrence and complications related to the trigger point injection were also recorded.

\section{Statistics}

Descriptive statistics for continuous variables were reported as the mean \pm standard deviation (SD) and analyzed using SPSS software, version 19.0 (IBM Corporation, Armonk, NY, USA). Differences between parameters were analyzed by the Student's $t$-test and the chi-square test. Correlation between parameters was analyzed by the Spearman's rank order correlation or the multivariate regression analysis. Recurrence and reinjection rate after first injection was computed using the Kaplan-Meier survival analysis. Effect of covariates on the relation with time to recurrence was evaluated using a Cox proportional hazards regression model. A $p$ value $<0.05$ was considered statistically significant.

\section{Results}

Among these 1,680 patients, 322 (19.2\%) patients complained of ocular pain as a part of their chief complaint. Based on the trigger point diagnostic criterion described in the "Methods" section, these 322 patients were further divided into 81 patients with and 241 patients without TC pain. These 81 patients with TC pain represented $4.8 \%$ of the total patients seen in a period of 8 years. Because of the subspecialty referral practice, the overwhelming majority of these 1,680 patients presented with a variety of active ocular surface diseases. Thus, it is of no surprise that ocular surface diseases were found in all 241 patients without TC pain and in 77 (95\%) patients with TC pain $(p=0.8)$. Normal ocular surface examination was noted in only $4(5 \%)$ patients with TC pain. As shown in Table 1, a comparison between these 2 groups did not reveal any difference in age, gender, prior surgery, prior topical medications, associated symptoms, or concomitant ocular or systemic diseases.

Table I Clinical data of patients with and without TC pain

\begin{tabular}{|c|c|c|c|}
\hline Demographic features & $\begin{array}{l}\text { TC pain } \\
n=81\end{array}$ & $\begin{array}{l}\text { Non-TC pain } \\
n=24 I\end{array}$ & $p$-value \\
\hline Age (years), mean \pm SD & $56.6 \pm 19.3$ & $58.7 \pm 20.7$ & 0.4 \\
\hline Gender (M:F) & $52: 29$ & $146: 95$ & 0.7 \\
\hline \multicolumn{4}{|l|}{ Prior surgery, $\mathrm{n}$ (\% of total) } \\
\hline Cataract & $7(8.6)$ & $40(16.6)$ & 0.1 \\
\hline Vitrectomy & $4(4.9)$ & $13(5.4)$ & 0.9 \\
\hline Blepharoplasty & $3(3.7)$ & $28(11.6)$ & 0.06 \\
\hline Tarsorraphy & $4(4.9)$ & $6(2.4)$ & 0.2 \\
\hline Limbal stem cell transplantation & $2(2.5)$ & $5(2.1)$ & 0.8 \\
\hline Refractive & $7(8.6)$ & $17(7.1)$ & 0.8 \\
\hline Superficial keratectomy & $\mathrm{I}(\mathrm{I} .2)$ & $7(2.9)$ & 0.7 \\
\hline Penetrating keratoplasty & $2(2.5)$ & $12(5)$ & 0.5 \\
\hline Conjunctivochalasis & $4(4.9)$ & II (4.6) & 0.9 \\
\hline Pterygium & $3(2.7)$ & $13(5.4)$ & 0.8 \\
\hline Strabismus & 0 & $2(0.8)$ & 0.6 \\
\hline Glaucoma & 0 & $12(4.5)$ & 0.6 \\
\hline Tumor excision & 0 & $3(1.2)$ & 0.6 \\
\hline Nasolacrimal & 0 & $3(1.2)$ & 0.6 \\
\hline Other & $5(6.2)$ & $24(9.9)$ & 0.5 \\
\hline
\end{tabular}


Table I (Continued)

\begin{tabular}{|c|c|c|c|}
\hline & $\begin{array}{l}\text { TC pain } \\
n=81\end{array}$ & $\begin{array}{l}\text { Non-TC pain } \\
n=241\end{array}$ & $p$-value \\
\hline \multicolumn{4}{|l|}{ Prior topical medication } \\
\hline Artificial tears & $21(25.6)$ & $80(33.2)$ & 0.5 \\
\hline Autologous serum & $4(4.9)$ & $16(6.6)$ & 0.2 \\
\hline Steroid & $17(21)$ & $84(34.9)$ & 0.08 \\
\hline Cyclosporine & $8(9.9)$ & 45 (18.7) & 0.09 \\
\hline Bandage contact lens & $7(8.6)$ & $34(14.1)$ & 0.4 \\
\hline Punctal occlusion & $20(24.7)$ & $46(19.1)$ & 0.6 \\
\hline \multicolumn{4}{|l|}{ Associated non-pain symptoms } \\
\hline Irritation & $38(47)$ & $82(34)$ & 0.08 \\
\hline Burning & $18(22.2)$ & $42(17.4)$ & 0.2 \\
\hline Dryness & $40(49.4)$ & $90(37.3)$ & 0.06 \\
\hline Tearing & $19(23.4)$ & $4 \mid(17)$ & 0.2 \\
\hline Blurred vision & $29(35.8)$ & $57(23.7)$ & 0.1 \\
\hline Photophobia & $22(27.2)$ & $49(20.3)$ & 0.2 \\
\hline Itching & $12(14.8)$ & $33(13.7)$ & 0.8 \\
\hline Mucus formation & $16(19.8)$ & $21(8.7)$ & 0.07 \\
\hline Redness & $14(17.3)$ & 45 (18.7) & 0.8 \\
\hline \multicolumn{4}{|l|}{ Concomitant ocular diseases } \\
\hline Dry eye disease & $40(49.4)$ & $94(39)$ & 0.3 \\
\hline Exposure keratopathy & $8(9.9)$ & $16(6.6)$ & 0.5 \\
\hline Lagophthalamus & $4(4.9)$ & $26(10.8)$ & 0.2 \\
\hline Blepharitis & $17(2 \mid)$ & $46(19.1)$ & 0.1 \\
\hline Conjunctivochalasis & $17(2 \mid)$ & $65(27)$ & 0.4 \\
\hline Sunken upper eyelids & $13(16)$ & $4 \mid(17)$ & 0.7 \\
\hline Eyelid disorder & $6(7.4)$ & $48(19.9)$ & 0.08 \\
\hline Limbal stem cell transplantation & $3(3.7)$ & $16(6.6)$ & 0.5 \\
\hline Symblepharon & $3(3.7)$ & $26(10.8)$ & 0.09 \\
\hline Pterygium & $3(3.7)$ & $16(6.6)$ & 0.5 \\
\hline Herpes zoster/simplex keratopathy & $3(3.7)$ & $5(2.1)$ & 0.3 \\
\hline Corneal ulcer & 0 & $13(5.4)$ & 0.2 \\
\hline Trauma & $2(2.5)$ & $10(4.1)$ & 0.7 \\
\hline Corneal perforation & $\mathrm{I}(\mathrm{I} .2)$ & $6(2.5)$ & 0.8 \\
\hline Floppy eyelid syndrome & $28(34.6)$ & $69(28.6)$ & 0.3 \\
\hline Glaucoma & $7(8.6)$ & $30(12.4)$ & 0.5 \\
\hline Chemical/thermal burn & $7(8.6)$ & $14(5.8)$ & 0.3 \\
\hline Medicamentosa & $3(3.7)$ & $2(0.8)$ & 0.2 \\
\hline Keratoconus & $\mathrm{I}(\mathrm{I} .2)$ & $4(1.7)$ & 0.2 \\
\hline Other & $14(17.3)$ & $5 I(21.2)$ & 0.1 \\
\hline \multicolumn{4}{|l|}{ Concomitant systemic diseases } \\
\hline Migraine & 0 & II (5) & 0.09 \\
\hline Cardiovascular & 0 & $3(1.2)$ & 0.7 \\
\hline Cancer/Tumor & $2(2.5)$ & $8(3.3)$ & 0.9 \\
\hline Autoimmune & $7(8.6)$ & $38(15.8)$ & 0.1 \\
\hline
\end{tabular}

Note: Data presented as case number $\mathrm{n}$ (\% of total) unless otherwise stated. Abbreviations: $F$, female; $M$, male; TC, trigeminal-cervical.

\section{Trigger points}

On examination, trigger points were elicited at the occipital region in all patients with TC pain (Figure 1A). Other trigger points were identified at the shoulder area where the trapezius muscle is attached (Figure 1C) and at the elbow area over the lateral epicondyle of the humerus bone (Figure 1D). Notable tenderness ipsilateral to the eye with ocular pain was also elicited by pressing the finger over these trigger points. Intriguingly, the location of the trigger points in the occipital region matched well with GB20 and GB12 acupuncture points (Figure 1E). Among 81 patients with TC pain, a trigger point was located at the occipital region alone in 27 patients (33.3\%), in both the occipital and the shoulder regions in 9 patients (11.1\%), in the occipital, shoulder, and elbow 
regions in 38 patients $(46.9 \%)$, and in the occipital and elbow regions in 7 patients (8.6\%) (Figure 1; Table 2). The ocular pain for these 81 patients was significantly more prevalent in unilateral TC pain $(n=63,77.8 \%)$ than those with asymmetric bilateral $(n=12,14.8 \%)(p \leq 0.001)$ or symmetric bilateral $(\mathrm{n}=6,7.4 \%)(p \leq 0.001) \mathrm{TC}$ pain. As expected, multivariate regression analysis showed that $\mathrm{TC}$ pain was significantly correlated with an ipsilateral trigger point $\left(f^{2}=99, p<0.001\right)$. That is, the trigger points of all 63 patients with unilateral TC pain were found on the same side as the eye with ocular pain. For all 12 patients with asymmetric bilateral ocular pain, the trigger points with more tenderness were also found in the ipsilateral eye with more severe ocular pain. In all 6 patients with symmetric bilateral pain, equal tenderness was noted on both sides of trigger points. Although similar laterality of ocular pain was noted in patients without TC pain regarding unilateral ocular pain $(n=131)$ and asymmetric bilateral
( $n=64)$ or symmetric bilateral $(n=46)$ ocular pain, none of them had trigger points in the aforementioned location.

\section{Pain characteristics}

Ocular pain observed in the 81 patients with TC pain persisted for some patients $(n=52,64.2 \%)$ despite having received additional systemic medications including oral analgesics $(n=32)$, non-steroidal anti-inflammatory agents $(n=15)$, antidepressants $(n=10)$, and carbamazepine $(n=10)$ or benzodiazepines $(n=7)$ for a mean duration of $17.4 \pm 22.9$ months before referral. Moreover, upon examination, such ocular pain was not relieved by topical anesthetics for any of the 81 patients with TC pain.

All 81 patients with TC pain complained of various intensities of persistent deep socket pain in retro-orbital and/ or supra-orbital areas, but no such complaints were made in patients without TC pain $(p<0.001$; Table 2$)$. Further inquiry

Table 2 Ocular pain characteristics in patients with and without TC pain

\begin{tabular}{|c|c|c|c|}
\hline Characteristics & $\begin{array}{l}\text { TC pain } \\
n=8 I \\
\text { Case number } n \text { (\% of total) }\end{array}$ & $\begin{array}{l}\text { Non-TC pain } \\
n=24 I \\
\text { Case number } n \text { (\% of total) }\end{array}$ & $p$-value \\
\hline \multicolumn{4}{|l|}{ Trigger points } \\
\hline Occipital region & $81(100)$ & 0 & $<0.001$ \\
\hline Shoulder & $47(58)$ & 0 & $<0.001$ \\
\hline Elbow & $45(55.6)$ & 0 & $<0.001$ \\
\hline \multicolumn{4}{|l|}{ Duration } \\
\hline Persistent between paroxysms & $81(100)$ & $13(5.4)$ & $<0.001$ \\
\hline Persistent & 0 & $68(28.2)$ & $<0.001$ \\
\hline Intermittent & 0 & $160(66.4)$ & $<0.001$ \\
\hline \multicolumn{4}{|l|}{ Ocular pain characteristics } \\
\hline Deep & $81(100)$ & $2(0.8)$ & $<0.001$ \\
\hline Superficial & 0 & 239 (99.2) & $<0.001$ \\
\hline Dull & $6(7.4)$ & $3(1.2)$ & 0.04 \\
\hline Sharp & $2(2.5)$ & $14(5.8)$ & 0.2 \\
\hline Throbbing & $3(3.7)$ & 0 & 0.03 \\
\hline Shooting & I (I.2) & I (0.4) & 0.4 \\
\hline Pressure & $5(6.2)$ & I (0.4) & $<0.001$ \\
\hline Pinch & 0 & I (0.4) & 0.7 \\
\hline Numbness & $2(2.5)$ & 0 & 0.02 \\
\hline Fluctuating & $6(7.4)$ & 0 & $<0.001$ \\
\hline \multicolumn{4}{|l|}{ Ocular pain location } \\
\hline Isolated in eye & $53(65.4)$ & $232(96.3)$ & $<0.001$ \\
\hline Associated with headache & $28(34.6)$ & $9(3.7)$ & 0.5 \\
\hline Frontal & $9(11.1)$ & $3(1.2)$ & \\
\hline Temporal & $12(14.8)$ & $5(2.1)$ & \\
\hline Occipital & $9(I I . I)$ & 0 & \\
\hline Facial & $5(6.2)$ & I (0.4) & \\
\hline Radiation to & & & 0.5 \\
\hline Ear & $4(4.9)$ & 0 & \\
\hline Neck & $3(3.7)$ & 0 & \\
\hline Teeth & $2(2.5)$ & 0 & \\
\hline Nose & $2(2.5)$ & 0 & \\
\hline Shoulder & $3(3.7)$ & 0 & \\
\hline
\end{tabular}

Abbreviation: TC trigeminal-cervical. 
revealed that TC pain in 58 of the 81 patients was characterized by solely deep ocular pain, which was significantly more than $(p<0.001)$ other associated pain characteristics including dull $(n=6)$, fluctuating $(n=6)$, pressure sensation $(n=5)$, throbbing $(n=3)$, sharp $(n=2)$, numbness $(n=2)$, and shooting $(n=1)$ pain in the remaining 23 patients. Two patients presented an overlap of pain characteristics such as dull combined with shooting or sharp pain, respectively. In contrast, only $2(0.8 \%)$ patients without TC pain described intermittent deep socket pain. Of the 241 patients without TC pain, 239 (99.2\%) showed superficial ocular pain. Importantly, 232 of $241(96.3 \%)$ patients without TC pain and 53 of $81(65.4 \%)$ patients with TC pain presented with isolated ocular pain that was limited only to the eye $(p<0.001)$ (Table 2$)$. Indeed, the remaining $28(34.6 \%)$ patients with TC pain presented predominate ocular pain associated with headaches and radiating pain. Multivariate regression analysis confirmed that TC pain was significantly correlated with persistent deep socket pain $\left(f^{2}=99, p<0.001\right)$ but not other pain characteristics such as headache or radiation pain $\left(f^{2}=0.09, p=0.5\right)$.

\section{Treatment}

All patients with TC pain were advised to use conservative treatments such as Bengay ${ }^{\circledR}$ (Johnson \& Johnson Consumer Companies, Inc., New Brunswick, NJ, USA), muscle rub, heat compress, or massage to trigger points. These treatments resulted in some extent of relief of ocular pain in 36 of the 81 patients. The remaining "unbearable" 45 patients receiving trigger point injection to the occipital region resulted

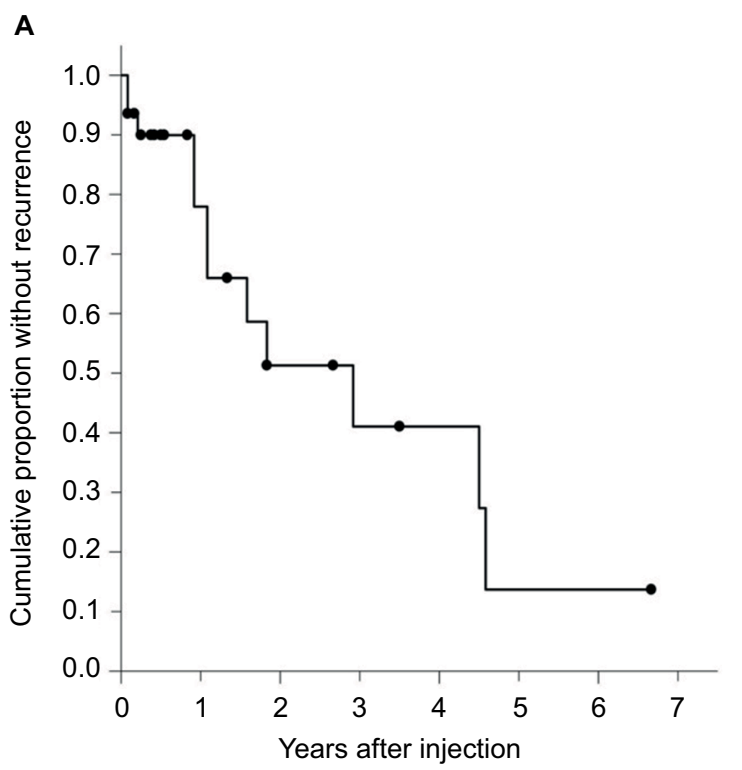

Figure 2 Kaplan-Meier analysis.

Notes: $(A)$ Ocular pain and $(B)$ reinjection recurrence after the first trigger point injection. in significant pain relief immediately or within a few days. The pain was completely relieved in 39 patients $(86.7 \%)$ and partially improved in 4 patients $(8.9 \%)$; however, there was no pain improvement noted in 2 patients (4.4\%). Kaplan-Meier survival analysis showed that the cumulative percentage of a symptom-free state after trigger point injection was $94 \%$ at 1 month, $90 \%$ at 3 months, $72 \%$ in 1 year, $51 \%$ in 2 years, and $41 \%$ in 3 years (Figure $2 \mathrm{~A}$ ). For those who recurred after the first injection, the reinjection rate was $9.5 \%$ at 1 month, $14 \%$ at 3 months, $29 \%$ in 1 year, $49 \%$ in 2 years, and $58 \%$ in 3 years (Figure 2B). For a mean follow-up duration of $16.2 \pm$ 19.1 months (range, 1-55 months) after the first injection, TC pain recurred in 12 patients $(26.7 \%)$, among whom 8 patients received a second injection, 3 patients received $>2$ injections, and 1 patient received 5 injections to achieve complete relief. No complications related to the injection were noted. Cox regression analysis showed that age $(p=0.6)$, gender $(p=0.6)$, prior surgery $(p=0.5)$, previous treatment $(p=0.8)$, concomitant systemic or ocular diseases $(p=0.9)$, ocular pain laterality $(p=0.7)$, and pain characteristics $(p=0.9)$ did not influence the recurrence rate (Table 3 ).

\section{Discussion}

Based on the presence of trigger point(s) criterion defined in the "Methods" section, we have identified 81 (4.8\%) patients with and 241 patients without TC pain in a total of 1,680 patients seen throughout a period of 8 years. The presence of trigger point(s) is indispensable for the diagnosis as we have confirmed the presence of trigger points based on tenderness

B

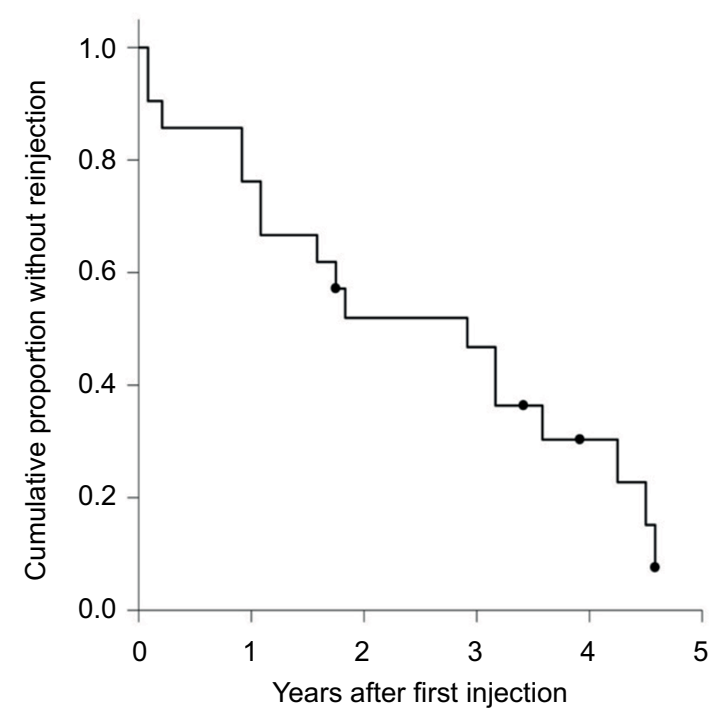


Table 3 Cox regression analysis of factors affecting recurrence of TC pain after trigger point injection

\begin{tabular}{|c|c|c|c|}
\hline Variable & $\begin{array}{l}\text { Hazard } \\
\text { ratio }\end{array}$ & $\begin{array}{l}95 \% \text { confidence } \\
\text { interval }\end{array}$ & $p$-value \\
\hline Age, years & 1.43 & $0.37-5.58$ & 0.6 \\
\hline \multicolumn{4}{|l|}{ Gender } \\
\hline Male & 1 & & \\
\hline Female & 1.02 & $0.43-3.52$ & 0.6 \\
\hline \multicolumn{4}{|l|}{ Prior surgery } \\
\hline No & 1 & & \\
\hline Yes & 0.90 & $0.21-3.32$ & 0.5 \\
\hline \multicolumn{4}{|c|}{ Prior treatments } \\
\hline No & 1 & & \\
\hline Yes & 1.99 & -2.47 to 6.44 & 0.8 \\
\hline \multicolumn{4}{|c|}{ Concomitant systemic diseases } \\
\hline No & 1 & & \\
\hline Yes & 0.64 & $0.05-8.37$ & 0.9 \\
\hline \multicolumn{4}{|c|}{ Concomitant ocular diseases } \\
\hline No & 1 & & \\
\hline Yes & 0.76 & $0.06-7.1$ & 0.9 \\
\hline \multicolumn{4}{|c|}{ Ocular pain laterality } \\
\hline Unilateral & I & & \\
\hline Bilateral & 0.26 & $0.016-4.29$ & 0.7 \\
\hline \multicolumn{4}{|c|}{ Pain characteristics } \\
\hline Deep & 1.12 & $0.75-3.19$ & 0.9 \\
\hline Others & 0.99 & $0.68-2.41$ & 0.9 \\
\hline
\end{tabular}

Abbreviation: TC trigeminal-cervical.

elicited by pressing by fingers over the ipsilateral external occipital protuberance in all 81 patients with TC pain. Our study further disclosed that TC pain had 100\% deep ocular pain in the retro-orbital or supraorbital area, while only $35 \%$ of our patients complained of headache, in which $11 \%$ were located at the occipital region. Patients with TC pain encountered infrequent headaches. The pattern of predominant ocular, but not occipital pain has also been described by Knox and Mustonen ${ }^{13}$ and adopted by others. ${ }^{14-16}$ Other than the presence of trigger point(s) and pain location, patients with TC pain also had deep ocular pain in the retro-orbital or supraorbital area that persisted between the paroxysms. Collectively, we believe the TC pain is a referred pain and is a new causative entity of ocular pain. Given the fact that patients reported herein seeking medical attention in the ocular surface center, their complaint of migraine headache was rather low. Further prospective studies are warranted to systemically test our hypothesis.

Interestingly, further comparative analyses disclosed that there was no difference in age, gender, prior surgeries, medications, and concomitant ocular diseases between patients with TC pain and those without. Because TC pain can be associated with many ocular diseases that are known to generate ocular pain and because comparative analyses also disclosed that there was no difference in non-pain symptoms, the diagnosis of TC pain can be overlooked and labeled as "under-estimated". Worst yet, without considering the extra-ocular (referred) cause such as TC pain, the complaint of ocular pain among all other non-ocular symptoms likely prompts ophthalmologists to overtreat the very concomitant ocular diseases. The lack of a notable relief following application of topical anesthetics in all our patients with TC pain can be differentiated from nociceptive and peripheral corneal neuropathy, ${ }^{17,18}$ which is also known to be frequently associated with concomitant ocular diseases. Unlike corneal neuropathic pain, the majority of pain therapies including those successfully directed to a central origin ${ }^{17}$ had also failed in our patients with TC pain.

We hereby provide the following algorithm in managing patients with complaints of ocular pain. First, a higher index of suspicion of TC pain should be raised when ocular pain persists between the paroxysms and is located deep at retro-orbital or supra-orbital areas. Such suspicion should be further elevated if the history-taking suggests that ocular pain remains refractory despite conventional anti-pain medications and topical anesthetics. Second, even if there are concomitant ocular surface diseases, physical examination should include palpation by finger pressing to identify ipsilateral trigger points (Figure 1). For those refractory patients, trigger points injection may be considered as an effective treatment. Consistent with previous reports, ${ }^{13-16}$ such trigger point injection achieved an effective relief of TC pain by breaking the cycle of trigemino-cervical coupling. Ocular pain relieved in majority of our patients with $\mathrm{TC}$ pain, in which most achieved immediate complete pain resolution with a low recurrence rate after trigger point injection. Because the assessment and treatments were performed by the same physician (ST), this study design eliminates inter-rater/examiner variability. However, our study is limited by not being controlled for other treatments during the 12 months and not including the notreatment control group. Because this study is retrospective in nature, the lack of significant adverse effects due to trigger point injection might be due to the lack of systematic query. Future prospective comparative studies will be strengthened by using an algometer to measure pain intensity of the trigger point to determine whether the said trigger point injection can help establish the diagnosis.

The underlying cause leading to TC pain remains unclear. Our correlative analysis, however, showed that TC pain was not correlated with systemic diseases such as migraine, cardiovascular, autoimmune diseases, and cancer/tumors, of which some may develop ocular pain by altering vascular, ${ }^{19,20}$ muscular, ${ }^{21}$ 
or neurological ${ }^{22,23}$ status of the tissues in the trigger points. We speculate that prolonged stretching of the muscles, e.g., trapezius muscle between the occipital bone and those in the shoulder, by a preferred sleeping posture on the bed might have been exacerbated by the lack of atonia. These collectively result in tissue/nerve inflammation at all said trigger points, triggering the said referred pain. Due to the retrospective nature of this study, future studies are warranted to validate this hypothesis to the pathogenic formation of trigger points in TC pain.

\section{Conclusion}

TC pain is a referred ocular pain that is characterized by persistent deep ocular pain with ipsilateral trigger points located at the occipital region. The clinical characteristics described herein helps differentiate from ocular pain caused by other etiologies and establish the correct diagnosis so that it will not be misdiagnosed or mislabeled as "undetermined" or as a reason to unnecessarily overtreat concomitant ocular diseases. By establishing TC pain as a new causative entity of ocular pain, patients suffering from ocular pain now can be better managed.

\section{Acknowledgments}

The authors thank Melissa Pena and Sean Tighe for assisting in editing the text. None of the authors have financial or proprietary interests in any material or method mentioned. This study was supported in part by an unrestricted grant from the Ocular Surface Research Education Foundation, Miami, FL, USA, and in part by grants S30205 from Shanghai Leading Academic Discipline Project from Shanghai, People's Republic of China.

\section{Disclosure}

The authors report no conflicts of interest in this work.

\section{References}

1. Perumal D, Niederer R, Raynel S, McGhee CN. Patterns of ophthalmic referral and emergency presentations to an acute tertiary eye service in New Zealand. N Z Med J. 2011;124(1340):35-47.

2. Belmonte C, Acosta MC, Merayo-Lloves J, Gallar J. What causes eye pain? Curr Ophthalmol Rep. 2015;3(2):111-121.

3. Burke RE. Sir Charles Sherrington's the integrative action of the nervous system: a centenary appreciation. Brain. 2007;130(pt 4):887-894.

Journal of Pain Research

Publish your work in this journal

The Journal of Pain Research is an international, peer reviewed, open access, online journal that welcomes laboratory and clinical findings in the fields of pain research and the prevention and management of pain. Original research, reviews, symposium reports, hypothesis formation and commentaries are all considered for publication.
4. Belmonte C. Eye dryness sensations after refractive surgery: impaired tear secretion or "phantom" cornea? J Refract Surg. 2007;23(6):598-602.

5. Headache Classification Committee of the International Headache Society (IHS). The International Classification of Headache Disorders, 3rd edition (beta version). Cephalalgia. 2013;33(9):629-808.

6. Piovesan EJ, Kowacs PA, Oshinsky ML. Convergence of cervical and trigeminal sensory afferents. Curr Pain Headache Rep. 2003;7(5): 377-383.

7. Okamoto K, Bereiter DF, Tashiro A, Bereiter DA. Ocular surface-evoked Fos-like immunoreactivity is enhanced in trigeminal subnucleus caudalis by prior exposure to endotoxin. Neuroscience. 2009;159(2):787-794.

8. Kurose M, Meng ID. Corneal dry-responsive neurons in the spinal trigeminal nucleus respond to innocuous cooling in the rat. JNeurophysiol. 2013;109(10):2517-2522.

9. Pergolizzi J, Ahlbeck K, Aldington D, et al. The development of chronic pain: physiological CHANGE necessitates a multidisciplinary approach to treatment. Curr Med Res Opin. 2013;29(9):1127-1135.

10. Fernandez-de-Las-Penas C, Cuadrado ML, Gerwin RD, Pareja JA. Referred pain elicited by manual exploration of the lateral rectus muscle in chronic tension-type headache. Pain Med. 2009;10(1):43-48.

11. Alonso-Blanco C, Fernandez-de-las-Penas C, Fernandez-Mayoralas DM, de-la-Llave-Rincon AI, Pareja JA, Svensson P. Prevalence and anatomical localization of muscle referred pain from active trigger points in head and neck musculature in adults and children with chronic tension-type headache. Pain Med. 2011;12(10):1453-1463.

12. Skillern PG. Great occipital-trigeminus syndrome as revealed by induction of block. AMA Arch Neurol Psychiatry. 1954;72(3):335-340.

13. Knox DL, Mustonen E. Greater occipital neuralgia: an ocular pain syndrome with multiple etiologies. Trans Sect Ophthalmol Am Acad Ophthalmol Otolaryngol. 1975;79(3 pt 2):513-519.

14. Bode DD Jr. Ocular pain secondary to occipital neuritis. Ann Ophthalmol. 1979;11(4):589-594.

15. Mason JO 3rd, Katz B, Greene HH. Severe ocular pain secondary to occipital neuralgia following vitrectomy surgery. Retina. 2004;24(3):458-459.

16. Selekler HM, Dundar G, Kutlu A. Görme bozukluğunun eşlik ettiği oksipital nevralji:Olgu sunumu [Occipital neuralgia with visual obscurations: a case report]. Agri. 2010;22(3):131-133. Turkish.

17. Goyal S, Hamrah P. Understanding neuropathic corneal pain-gaps and current therapeutic approaches. Semin Ophthalmol. 2016;31(1-2):59-70.

18. Aggarwal S, Kheirkhah A, Cavalcanti BM, et al. Autologous serum tears for treatment of photoallodynia in patients with corneal neuropathy: efficacy and evaluation with in vivo confocal microscopy. Ocul Surf. $2015 ; 13(3): 250-262$.

19. Hashiguchi A, Mimata C, Ichimura H, Kuratsu J. Occipital neuralgia as a presenting symptom of cervicomedullary dural arteriovenous fistula. Headache. 2007;47(7):1095-1097.

20. White JB, Atkinson PP, Cloft HJ, Atkinson JL. Vascular compression as a potential cause of occipital neuralgia: a case report. Cephalalgia. 2008;28(1):78-82.

21. Cox CL Jr, Cocks GR. Occipital neuralgia. J Med Assoc State Ala. 1979;48(7):23-27.

22. Garza I. Craniocervical junction schwannoma mimicking occipital neuralgia. Headache. 2007;47(8):1204-1205.

23. De SL, Monti L, Menci E, Bellini M, Annunziata P. Clinical-radiologic heterogeneity of occipital neuralgiform pain as multiple sclerosis relapse. Headache. 2009;49(2):304-307.

The manuscript management system is completely online and includes a very quick and fair peer-review system, which is all easy to use. Visit http://www.dovepress.com/testimonials.php to read real quotes from published authors. 